\title{
Study on the Stability of Existing Tunnel Influenced By Adjacent Undercrossing Construction
}

\author{
Zhifei Song ${ }^{1, a, ~}{ }^{*}, \mathrm{Fu} \mathrm{Yi}^{2,}$, , Di Sun ${ }^{2, \mathrm{c}}$ \\ ${ }^{1}$ School of Civil Engineering, North China University of Technology, Beijing, 100144, China \\ ${ }^{2}$ Institute of Civil Engineering and Transportation Liaoning Technical University, Fuxin 123000, \\ China \\ asong59672@163.com, byifu9716@163.com c1323715585@qq.com
}

Keywords: under construction, settlement, stress increment, Peck formula.

\begin{abstract}
This paper discusses the Dandong overlapping tunnel project in terms of the stability of existing tunnels by the approaching construction of overlapping tunnels. It uses the Peck formula and the theory of the Kinkler elastic foundation beam. The numerical model is established using MIDAS-GTS. The deformation process and the change in settlement and stress increment of the existing tunnel under the influence of the crossing construction were analyzed. Results clearly show the stability of the existing tunnels. The results show that during construction, under the influence of the crossing construction, existing tunnel displacement occurred mainly for vertical settlements, and showed a clear trend in settling tank. As the construction developed, there was a substantial difference between the horizontal and vertical settlements, and the lateral deformation had a strong directionality. The transverse stress increment was shown as a tensile stress increment, whereas the vertical was shown as a compressive stress increment. The safety of the existing tunnel was determined by combining this with the control standard value of the displacement and the stress increment. This method is applied to the construction of Dandong overlapping tunnels, which remedies the shortage in the experience design method, and provides a quantitative method to ensure the safety of the existing tunnel. This yields a reference value for the construction of overlapping tunnels.
\end{abstract}

\section{Foreword}

It is difficult to modify traffic lines within tunnels once construction is completed. The driving requirements in tunnels are generally many in number, but under-crossing construction will disturb the stratum and lead to safety and stability problems in existing tunnels. A considerable amount of information and engineering practices have showed ${ }^{[1-5]}$ that the disturbances produced by tunnel excavations exist in a specific range. Therefore, rational prediction of the stratum deformation produced by the under-crossing construction and its scope can enhance the safety and stability of tunnels ${ }^{[6-9]}$.

In terms of adjacent construction, Qiu ${ }^{[10]}$ analyzed the principles of mechanics of adjacent construction based on elastic-plastic theory, soil mechanics, rock mechanics, and tunnel mechanics; established a follow-up elastic grade beam model and a wall rock structure model; and proposed the concept of excavation influence line at the same time. Zheng ${ }^{[11]}$ studied different impacts and zones for predicting the thresholds of ground surface settlement through a large number of practical railway and road construction works, and thus obtained the adjacent influence zones of height-depth ratio (H/D), geometric proximity $\mathrm{A}$, or stress ratio $\left(R_{b} / \sigma_{0}\right)$. $\mathrm{Wu}^{[12]}$ used the mixed orthogonal method to analyze the proportion of each factor affecting under-crossing construction, and studied the rules of ground deformation after under-crossing construction of two tunnels simultaneously. $\mathrm{He}^{[13]}$ analyzed the variation of stress in wall rock and the variation trend in the internal force of support during under-crossing construction of a double-track tunnel by taking the subsidiary stress as a control index. Chen ${ }^{[14]}$ et al. analyzed the degree of influence of the under-crossing construction of an overlapped 
tunnel on the stability of an existing tunnel in terms of wall rock pressure, stress in support, and level of convergence.

Set against the backdrop of the Pandaoling under-crossing tunnel of Tangdan road, this study uses the finite element method to simulate and analyze the displacement and stress increment of existing tunnels caused by under-crossing construction, thus providing the necessary technical support for rational prediction of construction and the safety of existing tunnels.

\section{Prediction of tunnel deformation}

Numerous construction works, both locally and globally, have found that the affected tunnel presents some flexible deformation characteristics ${ }^{[11]}$. In such adjacent constructions, Professor Attewell believes that using linear elastic analysis can fulfill the construction requirements. It is assumed that the existing tunnel is an E. Winkle elastic continuous grade beam embedded in the stratum, and its differential equation of deflection is expressed as follows:

$E I \frac{d^{4} y}{d x^{4}}+k y=q_{(x)}$

Assuming that the stratum settlement after disturbance is $W_{d}$ and the settlement of the existing tunnel is $W_{s}$, the subsidiary force can be expressed as:

$q_{(x)}=K_{b} W_{d}$

The prediction of stratum settlement is expressed by the Peck formula:

$$
\begin{aligned}
& S(x)=S_{\max } \exp \left(-\frac{x^{2}}{2 i^{2}}\right) \\
& W_{d}=W_{d, \max } \exp \left(-b x^{2}\right) ; b=\frac{1}{2 i_{d}{ }^{2}}
\end{aligned}
$$

where $W_{d, \text { max }}$ is the maximal settlement of the stratum;

$\mathrm{i}_{d}$ is the width factor of the settlement trough of the stratum.

Because the existing tunnel presents flexible characteristics after settlement, the settlement curve form is considered the same as that of the stratum, seen in the following equation.

$W_{s}=W_{s, \max } \exp \left(-a x^{2}\right) \quad a=\frac{1}{2 i_{s}{ }^{2}}$

where $W_{s, \max }$ is the maximal settlement of the tunnel;

$\mathrm{i}_{\mathrm{s}}$ is the width factor of the settlement trough of the tunnel;

The following equation is obtained by substituting Eq. (4) and (5) into Eq. (3) and performing a Maclaurin expansion:

$$
\lambda^{4}+3 a^{2}-12 a^{3} x^{2}+4 a^{4} x^{4}=\lambda^{4} \frac{W_{d, \max }}{W_{s, \max }}\left[1+(a-b) x^{2}+\frac{(a-b)^{2} x^{4}}{2}\right]
$$

where $\lambda^{4}=\frac{K_{b}}{4(E I)_{P}}$

Solutions:

$\frac{a}{b}=0.6 ; \frac{W_{d, \max }}{W_{s, \max }}=1.2 ; \lambda=\sqrt[4]{15 a^{2}} ; \lambda=\sqrt[4]{\frac{27}{5}} b^{2}$

The relation between the width factors of the settlement troughs is expressed as the following:

$a=\frac{1}{\sqrt{15}} \lambda^{2}=\frac{1}{2 i_{s}^{2}}, \quad b=\sqrt{\frac{5}{27}} \lambda^{2}=\frac{1}{2 i_{d}^{2}}$

The tunnel-settlement prediction equation can be obtained by the following:

$W_{s}=W_{s, \max } \exp \left(-\frac{3}{10 i_{d}^{2}} x^{2}\right)=\frac{5}{6} W_{d, \max } \exp \left(-\frac{3}{10 i_{d}^{2}} x^{2}\right)$

The variation in the vertical settlement of the tunnel can be determined using Eq. (6). Thus, the degree of influence can be determined based on corresponding settlement thresholds and corresponding reinforcement measures can be taken. 


\section{Overview of construction}

The Pandaoling tunnel of Tangdan road is located in northwest Dandong, with an overall length of $620.0 \mathrm{~m}$. A new tunnel under-crossed the existing right-hand Pandaoling tunnel of Tangdan road at position TJLDK158+161, as shown in Fig. 1. The clear distance between these two tunnels is $4.47 \mathrm{~m}$ and their intersection (K5+146 K5+184) is a class $\mathrm{V}$ wall rock, which is broken to some extent. By inspecting the safety of the existing tunnel, the technical conditions of the tunnel in the inspection area (around the under-crossing segment) were rated as class B. The Drucker-Prager model was used to express the rock body in the model. The grid model of the tunnel is shown in Fig. 2 and the related parameters are listed in Table 1

Left tunnel of Tangdan road

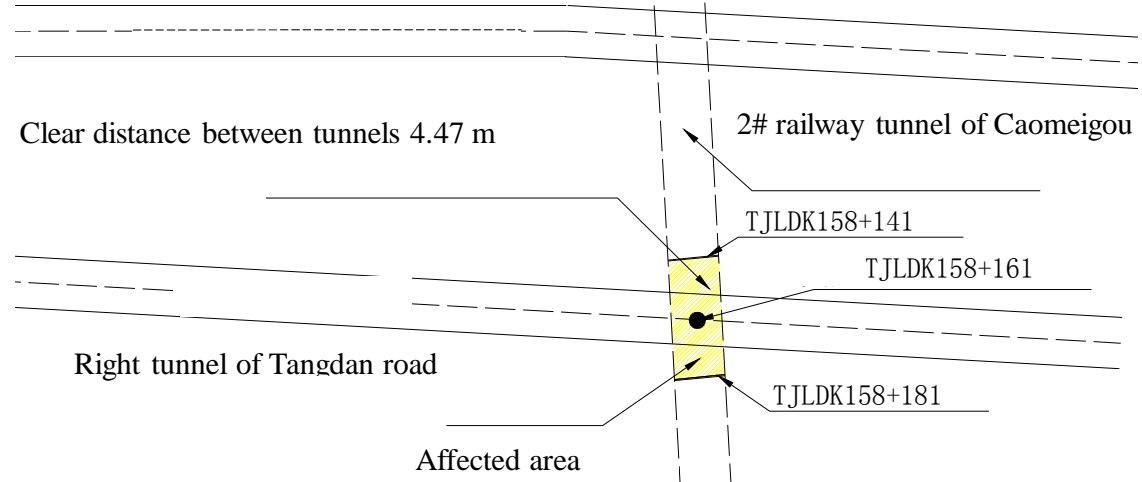

Fig. 1 Diagram of tunnel under-crossing

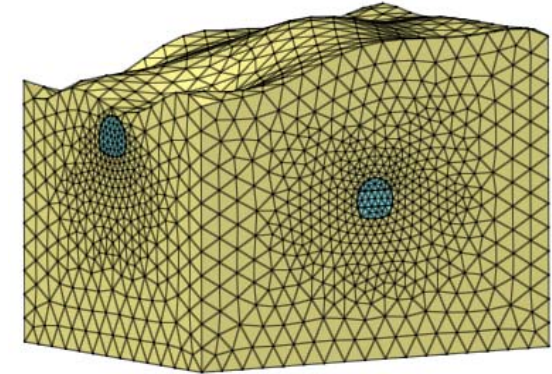

Fig. 2 Numerical model

Table 1 Physical and mechanical properties

\begin{tabular}{|c|c|c|c|c|c|}
\hline Material & $\begin{array}{c}\text { Elasticity } \\
\text { modulus/GPa }\end{array}$ & $\begin{array}{c}\text { Poisson's } \\
\text { ratio }\end{array}$ & $\begin{array}{c}\text { Unit } \\
\text { weight } \\
/ \mathrm{KN} / \mathrm{m} 3\end{array}$ & $\begin{array}{c}\text { Cohesion } \\
/ \mathrm{MPa}\end{array}$ & $\begin{array}{c}\text { Internal } \\
\text { friction } \\
\text { angle/ }\end{array}$ \\
\hline Wall rock & 1.3 & 0.32 & 21.5 & 0.12 & 27 \\
\hline Anchor rod & 200 & 0.3 & 78.5 & - & - \\
\hline Steel support & 206 & 0.5 & 30.75 & & - \\
\hline Initial shotcrete support & 0.028 & 0.2 & 24 & - & - \\
\hline $\begin{array}{c}\text { Support for cast-in-place } \\
\text { reinforced concrete }\end{array}$ & 31.5 & 0.25 & 25 & - & - \\
\hline
\end{tabular}

In the simulation analysis, the excavation and support of the tunnel were realized by the element activation and passivation functions of MIDAS-GTS; and the initial support and construction of the secondary lining were realized by extracting the tunnel elements twice. The new tunnel was constructed using the tri-bench method, with a bench length of $4 \mathrm{~m}$ and a drilling footage of excavation of $1 \mathrm{~m}$.

\section{Discriminant criteria for tunnel safety}

According to relevant regulations in the "Code for Design on Railway Tunnel," both the settlement and the horizontal displacement of a tunnel structure shall be less than $20 \mathrm{~mm}$. For some tunnels in special construction areas, the absolute settlement must be controlled in a range not exceeding $15 \mathrm{~mm}$. 
The relative deflection for tunnel settlement is also specified to be not more than $1 / 2500$. At present, the widely accepted empirical equation for the width of the settlement trough is expressed as $W=5 i$, and the relative deflection is used to control the maximal settlement of the tunnel which is $S \leq 5 \mathrm{i} / 5000$. Concerning the control standard for the stress increment, the allowable values of lining stress increase are specified in the "Guidelines for Adjacent Construction on Existing Railway Tunnels." The technical conditions of the existing tunnel in this construction were rated as class B, so the allowable tensile stress increment was $1 \mathrm{MPa}$ and the allowable compressive stress increment was $5 \mathrm{MPa}$.

Table 2 Allowable values of lining stress increase

\begin{tabular}{|c|c|c|}
\hline Soundness of existing tunnel & Tensile stress increment/MPa & Compressive stress increment/MPa \\
\hline AA & 0.3 & 1 \\
\hline A2, A1 & 0.5 & 2 \\
\hline B, S, C & 1 & 5 \\
\hline
\end{tabular}

\section{Simulated calculation results}

\subsection{Displacement analysis}

It can be seen from the longitudinal displacement nephogram of the existing tunnel (Fig. 3) that the longitudinal displacement increases when approaching the centerline cross-section in the lower tunnel. The settlement of the middle section in the existing tunnel (cross-section of existing tunnel directly above the new tunnel) is relatively larger. Data from each monitoring point on the middle section was analyzed, and the settlement curve of each monitoring point on the middle section during the entire construction of the lower tunnel is shown in Fig. 4.

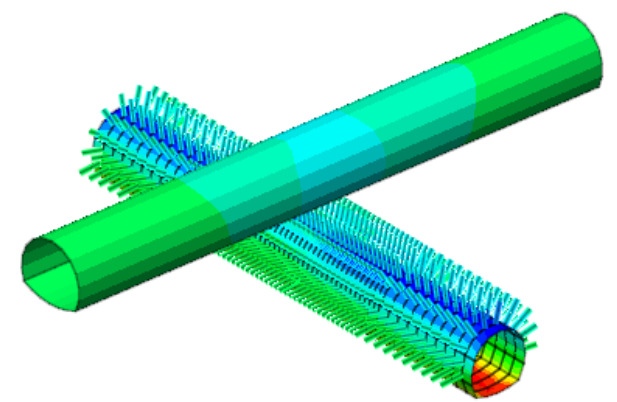

Fig. 3 Longitudinal displacement nephogram of two tunnels

The arch bottom, left and right haunches, and left and right arch springs on the middle section were significantly different from each other in the settlement. The right spring and haunch were the first to be settled because they were the first parts that contacted the excavating face, and the settlement changed rapidly when the footage of new tunnel was drilled to $20-40 \mathrm{~m}$. The left spring and haunch settled mainly when the footage was drilled to $40-60 \mathrm{~m}$. The bottom settled mainly when the footage was drilled to $30-50 \mathrm{~m}$, which is between the previous two footages. If the settlement is divided into four stages: slow settlement, rapid settlement, slow settlement, and stabilization, the segment with fast settlement is located in the area from the monitoring point to $1 D$ position ( $D$ is the outer diameter of the new tunnel) on the excavating face. Once the new tunnel was drilled through, the maximal settlement of the arch bottom of the existing tunnel was $1.33 \mathrm{~mm}$; the settlement of both the left and right springs was $1.12 \mathrm{~mm}$; and both the left and right haunches had the same minimal settlement of $1.01 \mathrm{~mm}$. 


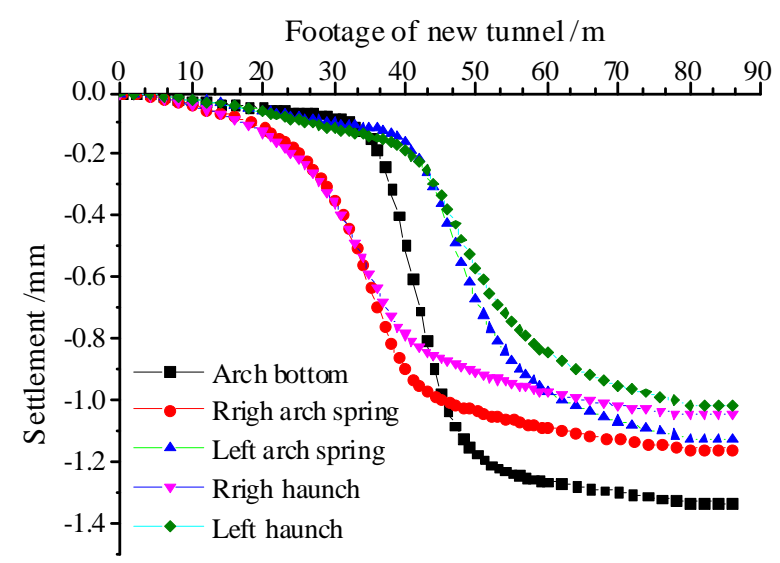

Fig. 4 Settling curves of middle section in existing tunnel

It can be seen from these final settlements that the arch bottom has maximal settlement and both the haunches have minimal settlement. In Fig. 5, it can be seen from analyzing the arch bottom settlement in the existing tunnel during construction that an evident settlement trough has been formed at the arch bottom. Using Eq. (6) for fitting, we obtain the width factor of the settlement trough as $\mathrm{i}=6.35$; thus, the width of the settlement trough is $\mathrm{w}=5 \mathrm{i}=31.75$. The allowable maximal settlement obtained based on the relative deflection of tunnel was $S=5 i / 5000=6.35$, whereas the maximal settlement of the arch bottom in the simulation was $1.33 \mathrm{~mm}$, which was far less than the settlement control threshold, therefore the existing tunnel is considered to be affected less in terms of displacement.

Distance to cave entrance with small landmark /m

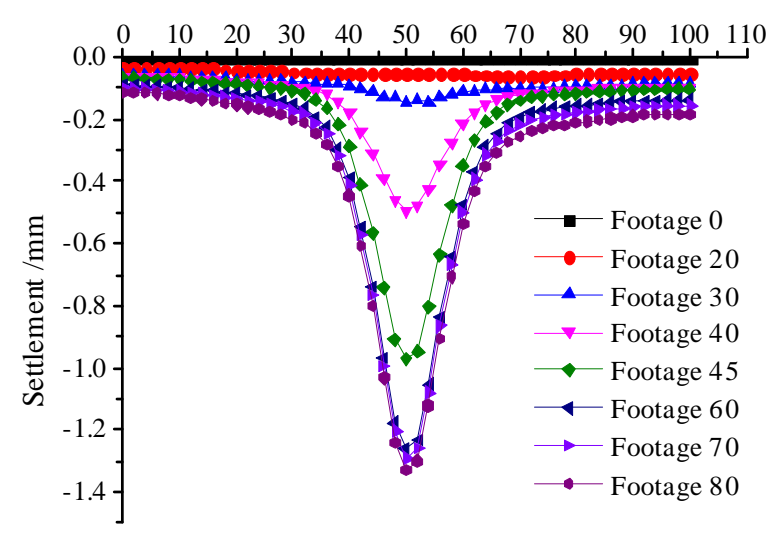

Fig. 5 Settlement curve of arch bottom

In addition to longitudinal settlement, obvious uneven transverse settlement also occurred on the cross-section of the tunnel during under-crossing. Transverse settlements of different footages are shown in Fig. 6; differential settling occurred on the cross-section of the existing tunnel and this process involved settling of the haunch and arch spring near the excavating face first, followed by settling of the arch bottom, and finally, settling of the opposite side. During the process of differential settling, the maximal differential settlement occurred when the excavating face was drilled to the position under the centerline of existing tunnel. Once the under-crossing construction was completed, a certain longitudinal settlement occurred on the cross-section of the tunnel while the differential settling faded away.

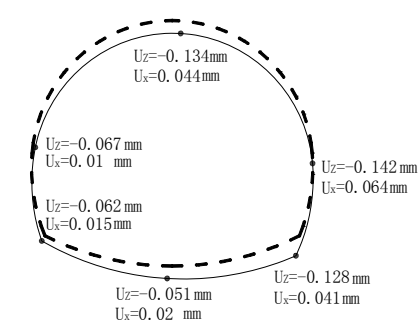

(a) Footage $20 \mathrm{~m}$

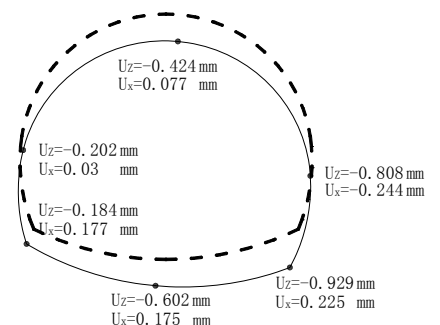

(b) Footage $40 \mathrm{~m}$

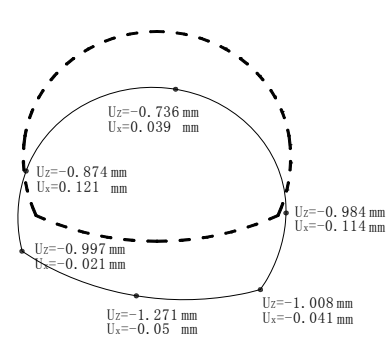

(c) Footage $60 \mathrm{~m}$

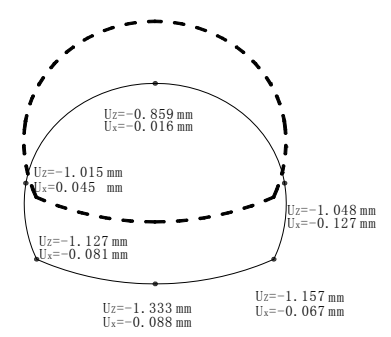

(d) Footage $80 \mathrm{~m}$

Fig. 6 Differential settlement diagrams of existing tunnel 
As the construction progressed, the lining convergence varied from section to section. Analyzing the convergence variation rules of the tunnel by taking the middle section and the right $5,10,15,20$, and $30 \mathrm{~m}$ sections as examples, the lining convergence curves are shown in Fig. 7 (positive values indicate section expansion and negative values indicate section reduction). It can be seen from the convergence diagrams of sections that different sections presented different characteristics during construction. The middle section firstly expanded and then reduced. As the distance to the middle section increases, the reduction trend of the section declines gradually. Once the distance reaches 15 $\mathrm{m}$, the sections always present an expansion trend, and as the distance increases, the expansion gradually decreases. The convergence of each section once drilling through the lower tunnel is shown in Fig. 8, where the middle section shows a reduction under compression and right sections beyond $7.5 \mathrm{~m}$ show expansion.

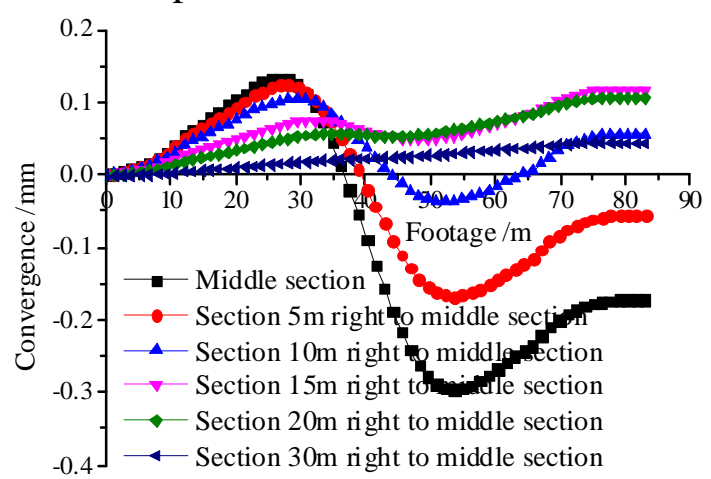

Fig 7 Convergence curves of cross-sections

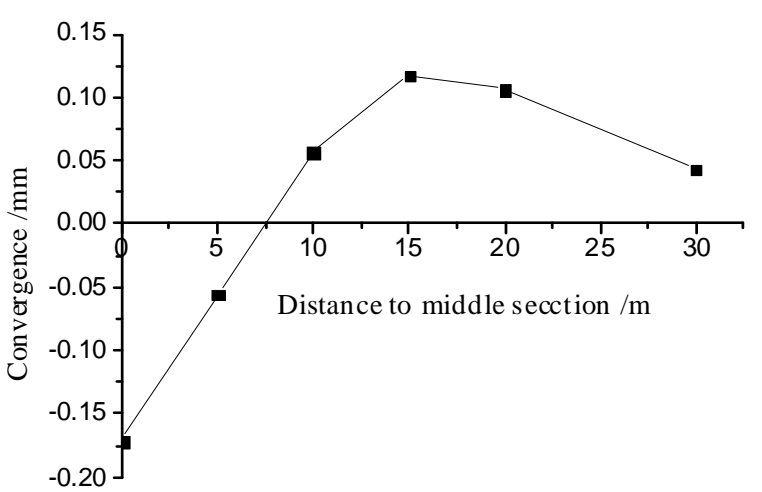

Fig. 8 Final convergences of cross-sections

\subsection{Stress increment analysis}

As the excavating face advanced continuously, the transverse force on the lining showed a tension trend. When the excavating face passed the $12 \mathrm{~m}$ section in the existing tunnel, the tensile stress at the right arch spring reached its maximum, $0.82 \mathrm{MPa}$. After that, the tensile stress increment at the right arch spring was stabilized at $0.68 \mathrm{MPa}$. It can be seen from Fig. 9 that all transverse stress increments after drilling through the tunnel were tensile stress increments.

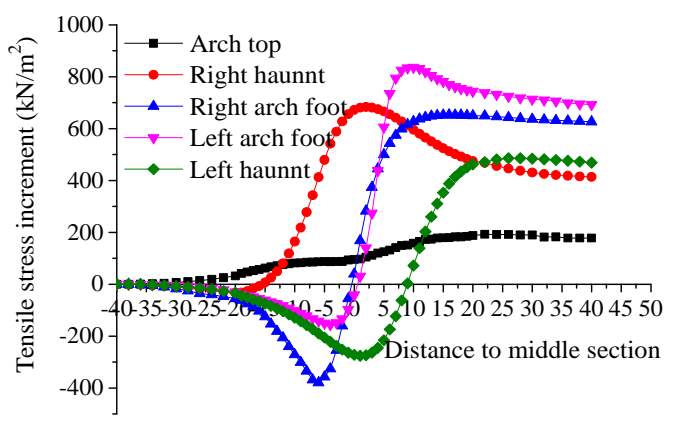

Fig. 9 Transverse stress increment curves on middle section

All longitudinal stress increments are compressive stress increments and the maximal stress increment was $0.5 \mathrm{MPa}$, which is far less than the compressive stress control threshold. Longitudinal stress increments are shown in Fig 10; the variation extent of the existing tunnel caused by the under-crossing construction was analyzed in terms of displacement and stress increment. The maximal displacement was $1.33 \mathrm{~mm}$, which is far less than the control threshold of $6.35 \mathrm{~mm}$. The maximal tensile stress increment was $0.68 \mathrm{MPa}$, which is less than the tensile stress control threshold of $1 \mathrm{MPa}$. The maximal compressive stress increment was $0.5 \mathrm{MPa}$, which is far less than the control threshold of $5 \mathrm{MPa}$. It can be predicted that the existing tunnel is less affected during under-crossing construction, and the new tunnel can be drilled through successfully. However, inspection at specified intervals and timely feedback of monitoring data during construction must be ensured to ensure $100 \%$ safety and stability for the existing tunnel. 


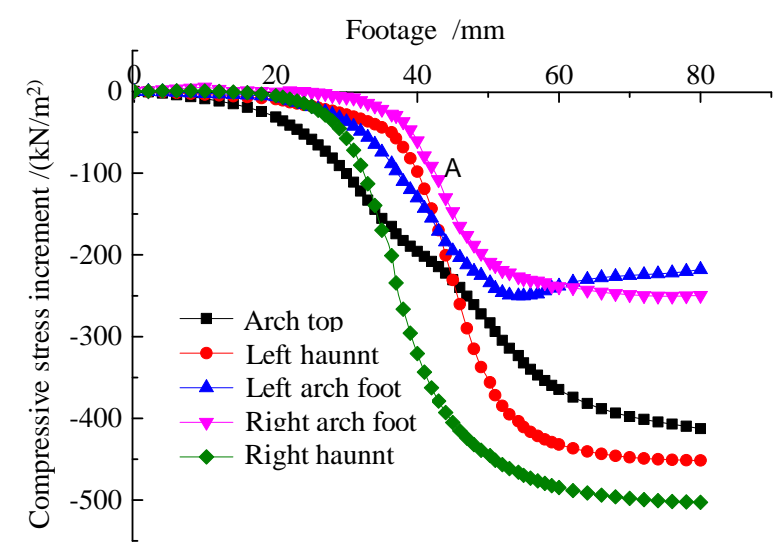

Fig. 10 Longitudinal stress increment curves on middle section

\section{Conclusion}

This study uses the theoretical analytical method combined with practical under-crossing construction of an overlapped tunnel in Dandong to analyze quantitatively the impact of under-passing construction on the safety and stability of an existing tunnel in terms of settlement and stress increment. The detailed research results are as follows:

(1) The elastic foundation theory was combined with the classical Peck equation to obtain the displacement variation equation for the existing tunnel under the action of under-crossing construction, and to further determine the affected area of existing tunnel.

(2) During under-crossing of the new tunnel, the displacement variation of the existing tunnel caused by cross-crossing is embodied mainly by vertical settlement, and shows a noticeable settlement trough trend. As the construction progresses, the difference between transverse and longitudinal settlements increases.

(3) After the tunnel is drilled through, the transversal and longitudinal stress increments are embodied by the tensile and compressive stress increments, respectively. Because values of both indices during construction are lower than the control thresholds, the affected degree of the existing tunnel during under-crossing construction can be predicted.

\section{References}

[1] H.X.PENG, Y.Y. CHENG, H.D. WANG. Analysis on Influence of Construction of Mining Tunnel on Nanjing-Hexian Inter-city Railway Crossing Underneath Existing Freight Railway Tunnel [J]. Tunnel Construction, 2014, 12:1137-1142.

[2] M. FANG, Z. LIU, C.Y. ZHOU. 3-D numerical simulation of influence of undercrossing shield construction on existing tunnel [J]. Journal of Railway Science and Engineering, 2011, 01:67-72.

[3] B. WU, B. SUO X.M. GAO. Study on influence of metro tunnel excavation on buried pipelines [J]. Rock and Soil Mechanics, 2004, 25(4): 657-662.

[4] J.C. WANG. Mechanical Response and Its Control of Overlying Existing Underground Structure with Shallow Tunnel Construction [D]. Beijing Jiaotong University, 2014.

[5] C.Y. Ou, R.N. Huang,W.J.Lai. Surface settlement during shield tunneling at CH218 in Taipei [J]. Canada Geotech./Rev.geotech. 1998, 35(1): 159-168.

[6] Manuel M, Luis M, Jose M., Prediction and analysis of subsidence induced by shield tunneling in the Madrid metro extension [J]. Canada Geotech. 2002, 39: 1273-1287.

[7] J.H. Shi, M.H. Zhong, L. He. Numerical simulation of ground sedimentation caused by double-tube parallel tunnels shielding constructed [J]. Journal of Safety Science and Technology, 2006, 2(3): 51-54.

[8] J.H. Shi. Safety analysis on metro station crossing through large underground space and metro tunnel $[\mathrm{J}]$. Journal of Safety Science and Technology, 2013, 9(5): 34-38. 
[9] Z.J. Lin. Study on the effect of construction of undercrossing shield tunnel on the existing high-speed railway tunnel and its control technology [D]. Central South University, 2013.

[10] W.G. QIU. The Study on Mechanics Principle and Countermeasure of Approaching Excavation in Underground Works[D]. Southwest Jiaotong University, 2003.

[11] Y.C. ZHENG. Study on the Inf1uence Degree of Adjacent Construction of Three Parallel Shield Tunnels [D]. Southwest Jiaotong University, 2007.

[12] K.S. WU. Research on the Mechanical Response of Overlapped Tunnels and the Deformation Control of Building in Qingdao Metro Construction [D]. Shandong University of Science and Technology, 2010.

[13] Q. He. Simulation of factors affecting stability of intersect tunnel by tunnel construction [D].Northwest A\&F University, 2015.

[14] W.Z. CHEN, D. ZHENG, J.X. YU. Study on Stability of Close Cross Tunnel on Existing Tunnel [J]. Chinese Journal of Rock Mechanics and Engineering, 2015, S1: 3097-3105.

[15] X. HAN, C.W. LIU, Jamie R. Standing. Structural settlement of existing tunnel caused by new tunnel excavated underneath [J]. China Civil Engineering Journal, 2012, 01: 134-141. 